\title{
The Flip Side of NIFTP: an Increase in Rates of Unfavorable Histologic Parameters in the Remainder of Papillary Thyroid Carcinomas
}

\author{
Kristine S. Wong ${ }^{1} \cdot$ Kyle C. Strickland $^{1} \cdot$ Trevor E. Angell $^{2} \cdot$ Matthew A. Nehs $^{3}$ • \\ Erik K. Alexander ${ }^{2}$ • Edmund S. Cibas ${ }^{1} \cdot$ Jeffrey F. Krane $^{1} \cdot$ Brooke E. Howitt $^{1}$ • \\ Justine A. Barletta ${ }^{1}$
}

Published online: 7 March 2017

(C) Springer Science+Business Media New York 2017

\begin{abstract}
The term noninvasive follicular thyroid neoplasm with papillary-like nuclear features (NIFTP) was recently proposed to replace noninvasive follicular variant of papillary thyroid carcinoma (FVPTC) both to promote more conservative management of these tumors and spare patients the psychological burden of a cancer diagnosis. This reclassification will lower the incidence of papillary thyroid carcinoma (PTC). In addition, it could result in an increase in the rates of unfavorable histologic prognosticators for PTC overall because NIFTPs had previously accounted for many of the PTCs without these features. Our aim was to evaluate the potential impact of the reclassification of NIFTP on the rates of extrathyroidal extension, lymphovascular invasion, and lymph node metastases in PTC. We identified all PTCs clinically over $1 \mathrm{~cm}$ diagnosed on surgical resection between August 2010 and August 2012. The histopathologic characteristics, including PTC subtype, tumor size, presence of extrathyroidal extension and lymphovascular invasion, and surgical margin and lymph node status were all recorded. Based on these parameters, cases were classified according to the American Thyroid Association (ATA) risk stratification system for structural disease recurrence. Tumor slides for cases initially diagnosed as FVPTC were reviewed to identify tumors that would now be classified as NIFTPs. Our cohort
\end{abstract}

Justine A. Barletta

jbarletta@partners.org

1 Department of Pathology, Brigham and Women's Hospital, Harvard Medical School, Boston, MA, USA

2 Division of Endocrinology, Brigham and Women's Hospital, Harvard Medical School, Boston, MA, USA

3 Department of Surgery, Brigham and Women's Hospital, Harvard Medical School, Boston, MA, USA included 348 cases of PTC, of which 94 (27\%) would now be classified as NIFTPs. After excluding NIFTPs from the PTC category, there were increased rates of extrathyroidal extension (26\% up from $19 \%, p=0.046)$, lymphovascular invasion (37\% up from $27 \%, p=0.0099$ ), and lymph node metastases (26\% up from $19 \%, p=0.045$ ) among the remaining PTCs. Based on these changes in histologic features, $10 \%$ fewer cases were defined as ATA low risk (62\% down from $72 \%$, $p=0.0081$ ). Our results indicate that the downgrading of some carcinomas to NIFTP will increase the rates of higher risk histologic parameters in the remaining PTCs by statistically significant margins. Although the overall survival for PTC is very high and would likely not be changed significantly by the introduction of NIFTP, additional studies evaluating the impact of the NIFTP shift are warranted.

Keywords Thyroid · NIFTP · Follicular variant of papillary thyroid carcinoma $\cdot$ Prognosis

\section{Introduction}

The term noninvasive follicular thyroid neoplasm with papillary-like nuclear features (NIFTP) was recently introduced to recognize the indolent behavior of thyroid neoplasms previously classified as noninvasive follicular variant of papillary thyroid carcinoma (FVPTC) [1]. These tumors are encapsulated or well circumscribed, have a follicular architecture, and have "papillary-like" nuclear features, including nuclear enlargement, contour irregularities, grooves, and clearing [1-4]. By definition, NIFTPs lack capsular penetration, lymphovascular invasion, extrathyroidal extension, and lymph node metastases. Molecularly, they predominantly harbor $R A S$ mutations, though a smaller subset has been found to 
have the BRAF K601E mutation and PPARG and THADA fusions $[1,5,6]$. In the last several decades, FVPTC has accounted for an increasing percentage of papillary thyroid carcinoma (PTC). Jung and colleagues reported that FVPTCs accounted for $10 \%$ of all PTCs diagnosed at the University of Pittsburgh between 1974 and 1985 (with classical PTC accounting for 52\%), but for $25 \%$ of PTCs diagnosed in 2009 (with classical PTCs accounting for 19\%, and the bulk of the remaining tumors classified as microcarcinomas) [7]. This study was conducted prior to the characterization of NIFTP; however, it is likely that a significant subset of the tumors would represent NIFTPs. In the few studies that have evaluated the impact of NIFTP on thyroid carcinoma diagnoses, tumors previously diagnosed as noninvasive FVPTC (now NIFTP) accounted for between 9 and 25\% of thyroid carcinomas [3, 8-10]. Although the introduction of the NIFTP nomenclature was aimed to reduce the overtreatment of an indolent thyroid tumor and spare patients the psychological burden of a cancer diagnosis [1,11], the introduction of NIFTP will have additional consequences. Our group and others have previously reported the impact that the introduction of NIFTP could have on fine needle aspiration diagnoses, with NIFTP decreasing the risk of malignancy for all Bethesda diagnostic categories [8,10,12]. Additionally, the emergence of NIFTP will also affect the interpretation of molecular testing of thyroid nodules [13-15]. The introduction of NIFTP could potentially also result in an increase in the rates of unfavorable histologic prognosticators for the remaining PTCs because NIFTPs had previously accounted for a significant subset of PTCs without these features. Our aim was to evaluate the potential impact of the reclassification of NIFTP on rates of extrathyroidal extension, lymphovascular invasion, margin status, and lymph node metastases in PTC. Additionally, we assessed how the changes in histologic parameters would affect risk stratification for structural disease recurrence according to the American Thyroid Association (ATA) guidelines.

\section{Materials and Methods}

\section{Study Population and Data Acquisition}

Approval from the Brigham and Women's Hospital investigation review board was obtained. From a database of thyroid resection specimens received between August 2010 and August 2012, we retrospectively identified 348 cases which were diagnosed as PTC. For each case, demographic and clinical information (including age, gender, and type of surgery) and histopathologic characteristics (including tumor size and location, extrathyroidal extension, lymphovascular invasion, surgical margin status, and lymph node status) were obtained from the pathology reports.
Tumor slides for cases diagnosed as FVPTC on resection were reviewed to identify tumors that would now be categorized as NIFTP. Tumors diagnosed as FVPTC had an entirely or nearly entirely follicular architecture $(<1 \%$ papillae) and "papillary-like" nuclear features (including nuclear enlargement, elongation, contour irregularities, grooves, and clearing). NIFTPs included encapsulated tumors with a complete fibrous capsule separating the tumor from the surrounding benign parenchyma and partially-encapsulated/wellcircumscribed tumors that had a partial capsule or entirely lacked a capsule but had a sharp interface between the tumor and benign parenchyma. FVPTCs that had infiltrative growth, capsular penetration, or lymphovascular invasion were classified as infiltrative/invasive FVPTC. An example of a tumor that would now be characterized as NIFTP is shown in Fig. 1.

\section{ATA Risk Stratification}

Tumors were classified according to the ATA risk stratification system for structural disease recurrence [16]. Low-risk tumors were intrathyroidal tumors with $\leq 5$ lymph node micrometastases $(<0.2 \mathrm{~cm}$ in size). Intermediate risk tumors were those with aggressive histology (such as tall cell variant), microscopic extrathyroidal extension, $>5$ lymph node metastases, lymph node metastases $\geq 0.2 \mathrm{~cm}$ but $<3 \mathrm{~cm}$ in size, or lymph node metastases with extranodal extension. High-risk tumors were those with gross extrathyroidal extension, incomplete tumor resection, or with any metastatic lymph node $\geq 3 \mathrm{~cm}$ in size. Determination of gross extrathyroidal extension and incomplete tumor resection was based on the surgical operative note in the patient medical record.

\section{Statistical Analysis}

Correlations were determined using Fisher's exact test or unpaired $t$ test, as appropriate. $p$ Values less than 0.05 were determined to be statistically significant. Statistical analysis was performed using Prism (GraphPad Software, Inc., La Jolla, CA).

\section{Results}

A total of 348 cases which had been diagnosed as PTC on surgical resection were identified. Of these patients, $82(24 \%)$ were men and 266 (76\%) were women, with a mean age of 48 years at the time of resection (range 18-83 years). Seventyfive $(22 \%)$ patients underwent partial or hemithyroidectomy, while $273(78 \%)$ had a total or near total thyroidectomy. Lymph nodes were sampled in $222(64 \%)$ cases. Of the 348 cases, FVPTC accounted for $132(38 \%)$ cases, classical type $163(47 \%)$ cases, tall cell variant $27(8 \%)$ cases, and other 


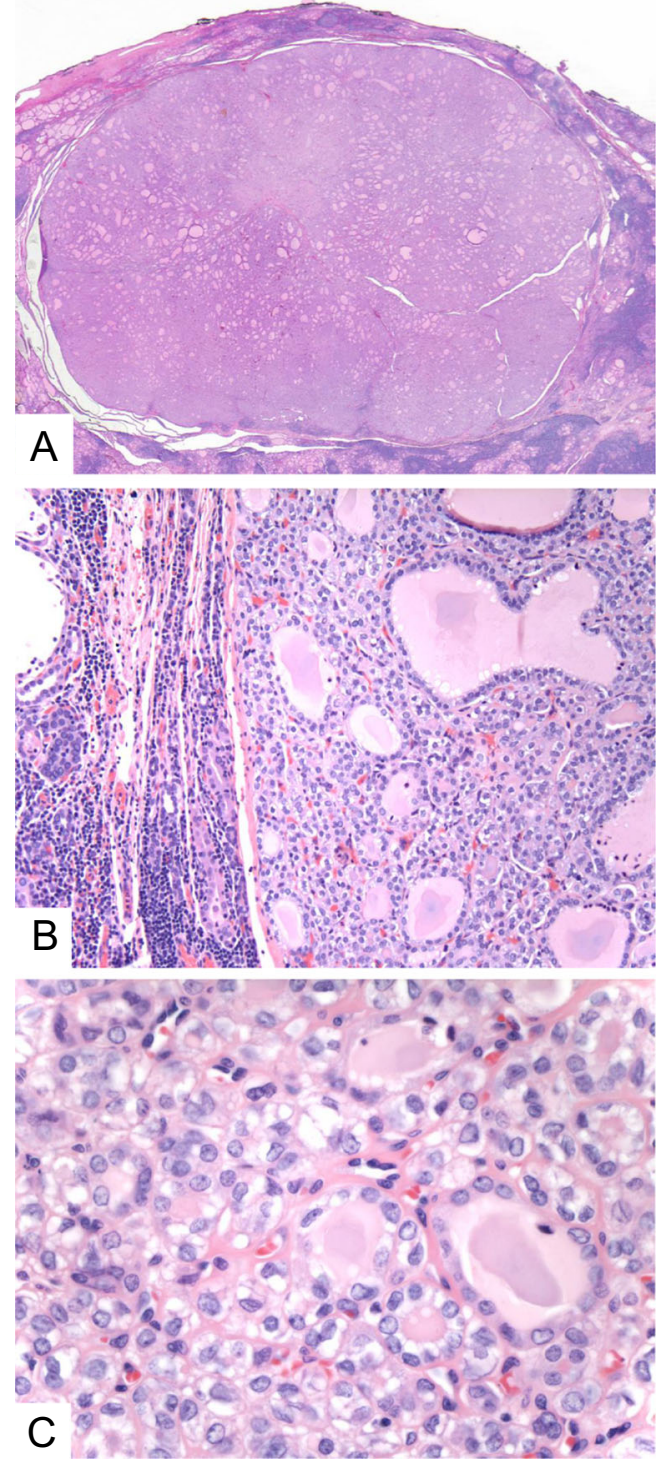

Fig. 1 Example of a noninvasive follicular thyroid neoplasm with papillary-like nuclear features (NIFTP). a The tumor is very well circumscribed and has an entirely follicular architecture. b There is a sharp interface between the tumor and benign parenchyma. c "Papillary-like" nuclear features are present (including nuclear enlargement, contour irregularities, grooves, and clearing)

variants $26(7 \%)$ cases. Of the 132 cases diagnosed as FVPTC, $94(71 \%)$ would now be classified as NIFTP.

The clinicopathologic characteristics of the entire cohort and of PTCs excluding NIFTPs are summarized in Table 1. For the entire cohort, the mean tumor size was $2.0 \mathrm{~cm}$. Extrathyroidal extension was present in $66(19 \%)$ cases, lymphovascular in 94 (27\%) cases, and positive surgical resection margins in $39(11 \%)$ cases. Lymph node metastases were present in $65(19 \%)$ cases. When excluding NIFTP, there were 254 remaining PTCs, which were from $63(25 \%)$ male and $191(75 \%)$ female patients with a mean age of 47 years (range 18-83 years). The mean tumor size was $1.9 \mathrm{~cm}$. Extrathyroidal extension was seen in $66(26 \%)$ cases,
Table 1 Clinicopathologic characteristics of study patients

\begin{tabular}{llll}
\hline Characteristic & Entire cohort & PTCs excluding NIFTP & $p$ value \\
\hline Sex $(n(\%))$ & & & \\
$\quad$ Female & $266(76)$ & $191(75)$ & 0.77 \\
$\quad$ Male & $82(24)$ & $63(25)$ & \\
Age (years) & & & \\
$\quad$ Mean & 48 & 47 & \\
Range & $18-83$ & $18-83$ & 0.10 \\
Mean tumor size (cm) & 2.0 & 1.9 & 0.046 \\
Extrathyroidal extension $(n(\%))$ & & \\
Present & $66(19)$ & $66(26)$ & 0.0099 \\
Absent & $282(81)$ & $188(74)$ & \\
Lymphovascular invasion $(n(\%))$ & & 0.045 \\
Present & $94(27)$ & $94(37)$ & \\
Absent & $254(73)$ & $160(63)$ & 0.14 \\
Lymph node metastases $(n(\%))^{\mathrm{a}}$ & & \\
Present & $65(19)$ & $65(26)$ & \\
Absent & $283(81)$ & $189(74)$ & \\
Surgical margin status $(n(\%))$ & & $39(15)$ & \\
Positive & $39(11)$ & $215(85)$ & \\
Negative & $309(89)$ & & \\
\hline
\end{tabular}

PTC papillary thyroid carcinoma, NIFTP noninvasive follicular thyroid neoplasm with papillary-like nuclear features

${ }^{\text {a }}$ Lymph nodes were sampled in only 222 patients from the entire cohort and 179 patients when excluding NIFTP

lymphovascular invasion was present in $94(37 \%)$ cases, and a positive resection margin was present in $39(15 \%)$ cases. Lymph node metastases were present in 65 (26\%) cases. The mean number of positive lymph nodes was 6 (range 1-38). For cases in which the size of the largest lymph node metastasis was recorded (98\%), the mean size of the largest lymph node metastasis was $1.0 \mathrm{~cm}$ (range $<0.1-5.5 \mathrm{~cm}$ ). Eleven cases showed extranodal extension. When comparing the entire cohort and PTCs excluding NIFTPs, there were increased rates of extrathyroidal extension (26\% up from $19 \%$, $p=0.046$ ), lymphovascular invasion (37\% up from $27 \%$, $p=0.0099$ ), and lymph node metastases (26\% up from $19 \%, p=0.045)$. There was no difference in the rates of positive surgical resections margins detected histologically (11 to $15 \%, p=0.14$ ).

The ATA risk stratification of the entire cohort and of PTCs excluding NIFTPs is summarized in Table 2. For the entire cohort, $251(72 \%)$ cases were low risk, 84 (24\%) were intermediate risk, and 13 (4\%) were high risk. When excluding NIFTPs, 157 (62\%) cases were low risk, 84 (33\%) were intermediate risk, and $13(5 \%)$ were high risk. When comparing the proportion of cases in each risk category between the entire cohort and PTCs excluding NIFTPs, there was a decrease in low-risk cases $(62 \%$ down from $72 \%, p=0.0081)$ and increase in intermediate-risk cases (33\% up from 24\%, $p=0.017$ ). There was no difference in high-risk cases ( 4 to $5 \%, p=0.42$ ). 
Table 2 American Thyroid Association risk stratification of study patients

\begin{tabular}{llll}
\hline Risk category & Entire cohort & PTCs excluding NIFTP & $p$ value \\
\hline ATA low risk $(n(\%))$ & $251(72)$ & $157(62)$ & 0.0081 \\
ATA intermediate risk $(n(\%))$ & $84(24)$ & $84(33)$ & 0.017 \\
ATA high risk $(n(\%))$ & $13(4)$ & $13(5)$ & 0.42 \\
\hline
\end{tabular}

Cases were categorized as low, intermediate, or high risk based on the ATA risk stratification system for structural disease recurrence

ATA American Thyroid Association, PTC papillary thyroid carcinoma, NIFTP noninvasive follicular thyroid neoplasm with papillary-like nuclear features

\section{Discussion}

The aim of our study was to evaluate the potential impact of the reclassification of NIFTP on rates of unfavorable histologic parameters in the remainder of PTCs. We found that the downgrading of some carcinomas to NIFTP resulted in increased rates of extrathyroidal extension, lymphovascular invasion, and lymph node metastases among the remaining PTCs by statistically significant margins. These changes in histologic parameters translated into a significant decrease in the number of cases that would be categorized as low risk according to the ATA risk stratification system for structural disease recurrence. These findings are not surprising given the lack of aggressive histopathologic features inherent to the NIFTP diagnosis, which by definition does not have lymphovascular invasion, extrathyroidal extension, or lymph node metastases. However, the potential relative increase in these features in the remainder of PTCs is important to demonstrate since it could affect the overall prognosis for patients with PTC or translate into a larger proportion of PTC patients that receive radioactive iodine (RAI) in addition to surgery. For example, the presence of lymph node metastases has been shown to affect prognosis both in older and younger patients $[17,18]$. The magnitude of this impact is small, with Adam and colleagues showing that in patients younger than 45 , the overall survival at 10 years was $98.2 \%$ among those without nodal metastases and $97.8 \%$ among those with nodal metastases [17]. Thus, an increase in the proportion of PTC patients with lymph node metastases due to the NIFTP shift may or may not affect prognosis. Moreover, any change in prognosis would likely only be demonstrable in large cohorts with significant follow-up time. Although the prognostic significance of extrathyroidal extension depends on the amount of extrathyroidal extension present $[6,19,20]$, the presence of even minor extrathyroidal extension puts patients into the ATA's intermediate risk of structural disease recurrence category [16]. Consequently, many, if not most, of these patients are given RAI. It is important to emphasize that the magnitude of the impact of NIFTP will differ between countries and between hospitals within the same country. Previously, it was shown that there was significant interobserver variability in the FVPTC diagnosis, largely due to differences in what was considered sufficient PTC nuclear features [21-23]. In the few studies that have retrospectively evaluated the number of thyroid carcinomas that would now be classified as NIFTP, NIFTP accounted for $9-25 \%$ of carcinomas [8-10]. More studies are needed in order to better estimate the impact of NIFTP, both at academic centers and in community practices, in different regions of the USA, and in different countries.

It is likely that the introduction of the NIFTP nomenclature will change other PTC characteristics. For example, the molecular profile of PTC will probably change. NIFTPs lack the $B R A F$ V600E mutation and instead predominantly harbor $R A S$ mutations, though a smaller subset has been found to have the BRAF K601E mutation and PPARG and THADA fusions $[1,5,6,24]$. NIFTPs account for the majority of PTCs with $R A S$ mutations [13]. Thus, the remainder of PTCs will likely have an increased rate of the $B R A F$ V600E mutation and a lower rate of $R A S$ mutations. The majority of studies evaluating PTCs in adults have shown that $B R A F$ V600E mutation is associated with high-risk histopathologic features, such as increased frequency of extrathyroidal extension, lymph node metastases, and higher clinical stage [25-29]. In contrast, RAS mutations are often associated with more low-risk features [30,31]. Our findings, at least in part, likely reflect an increase in the number of PTCs harboring a $B R A F$ V600E mutation. Finally, the BRAF V600E mutation has been linked to RAI resistance. Thus, the introduction of NIFTP could potentially affect the efficacy rate of RAI. More studies are needed to investigate these issues.

In summary, we demonstrated that in our cohort of PTCs the NIFTP shift resulted in increased rates of extrathyroidal extension, lymphovascular invasion, and lymph node metastases. Additional multi-institutional studies are needed to confirm these findings.

Compliance with Ethical Standards The study has been performed according to the Declaration of Helsinki. IRB approval was obtained. Informed consent was not required for our study.

Conflict of Interest The authors declare that they have no conflict of interest. 


\section{References}

1. Nikiforov YE, Seethala RR, Tallini G, Baloch ZW, Basolo F, Thompson LDR, Barletta JA, Wenig BM, Al Ghuzlan A, Kakudo K, Giordano TJ, Alves VA, Khanafshar E, Asa SL, El-Naggar AK, Gooding WE, Hodak SP, Lloyd RV, Maytal G, Mete O, Nikiforova MN, Nosé V, Papotti M, Poller DN, Sadow PM, Tischler AS, Tuttle RM, Wall KB, LiVolsi VA, Randolph GW, Ghossein RA (2016) Nomenclature Revision for Encapsulated Follicular Variant of Papillary Thyroid Carcinoma: A Paradigm Shift to Reduce Overtreatment of Indolent Tumors. JAMA oncology 2:1023-1029

2. Liu J, Singh B, Tallini G, Carlson DL, Katabi N, Shaha A, Tuttle RM, Ghossein RA (2006) Follicular variant of papillary thyroid carcinoma. Cancer 107:1255-1264

3. Thompson LDR (2016) Ninety-four cases of encapsulated follicular variant of papillary thyroid carcinoma: A name change to Noninvasive Follicular Thyroid Neoplasm with Papillary-like Nuclear Features would help prevent overtreatment. Modern Pathology 29:698-707

4. Vivero M, Kraft S, Barletta JA (2012) Risk Stratification of Follicular Variant of Papillary Thyroid Carcinoma. Thyroid 23: 273-279

5. Howitt BE, Jia Y, Sholl LM, Barletta JA (2013) Molecular Alterations in Partially-Encapsulated or Well-Circumscribed Follicular Variant of Papillary Thyroid Carcinoma. Thyroid 23: $1256-1262$

6. Rivera M, Ricarte-Filho J, Knauf J, Shaha A, Tuttle M, Fagin JA, Ghossein RA (2010) Molecular genotyping of papillary thyroid carcinoma follicular variant according to its histological subtypes (encapsulated vs infiltrative) reveals distinct BRAF and RAS mutation patterns. Modern Pathology 23:1191-1200

7. Jung CK, Little MP, Lubin JH, Brenner AV, Wells SA, Jr., Sigurdson AJ, Nikiforov YE (2014) The increase in thyroid cancer incidence during the last four decades is accompanied by a high frequency of BRAF mutations and a sharp increase in RAS mutations. J Clin Endocrinol Metab 99:E276-E285

8. Faquin WC, Wong LQ, Afrogheh AH, Ali SZ, Bishop JA, Bongiovanni M, Pusztaszeri MP, VandenBussche CJ, Gourmaud J, Vaickus LJ, Baloch ZW (2016) Impact of reclassifying noninvasive follicular variant of papillary thyroid carcinoma on the risk of malignancy in The Bethesda System for Reporting Thyroid Cytopathology. Cancer Cytopathol 124:181-187

9. Likhterov I, Osorio M, Moubayed SP, Hernandez-Prera JC, Rhodes R, Urken ML (2016) The Ethical Implications of the Reclassification of Noninvasive Follicular Variant Papillary Thyroid Carcinoma. Thyroid 26:1167-1172

10. Strickland KC, Howitt BE, Marqusee E, Alexander EK, Cibas ES, Krane JF, Barletta JA (2015) The Impact of Noninvasive Follicular Variant of Papillary Thyroid Carcinoma on Rates of Malignancy for Fine-Needle Aspiration Diagnostic Categories. Thyroid 25:987992

11. Hodak S, Tuttle RM, Maytal G, Nikiforov YE, Randolph G (2016) Changing the Cancer Diagnosis: The Case of Follicular Variant of Papillary Thyroid Cancer-Primum Non Nocere and NIFTP. Thyroid 26:869-871

12. Maletta F, Massa F, Torregrossa L, Duregon E, Casadei GP, Basolo F, Tallini G, Volante M, Nikiforov YE, Papotti M (2016) Cytological features of "noninvasive follicular thyroid neoplasm with papillary-like nuclear features" and their correlation with tumor histology. Hum Pathol 54:134-142

13. Paulson VA, Shivdasani P, Angell TE, Alexander EK, Cibas E, Krane JF, Lindeman NI, Barletta J (2017) NIFTP Accounts for Over Half of "Carcinomas" Harboring RAS Mutations. Thyroid Epub ahead of print
14. Valderrabano P, Khazai L, Leon ME, Thompson ZJ, Ma Z, Chung $\mathrm{CH}$, Hallanger-Johnson JE, Otto KJ, Rogers KD, Centeno B, McIver B (2017) Evaluation of ThyroSeq v2 performance in thyroid nodules with indeterminate cytology. Endocr Relat Cancer

15. Wong KS, Angell TE, Strickland KC, Alexander EK, Cibas ES, Krane JF, Barletta JA (2016) Noninvasive Follicular Variant of Papillary Thyroid Carcinoma and the Afirma Gene-Expression Classifier. Thyroid 26:911-915

16. Haugen BR, Alexander EK, Bible KC, Doherty GM, Mandel SJ, Nikiforov YE, Pacini F, Randolph GW, Sawka AM, Schlumberger M, Schuff KG, Sherman SI, Sosa JA, Steward DL, Tuttle RM, Wartofsky L (2016) 2015 American Thyroid Association Management Guidelines for Adult Patients with Thyroid Nodules and Differentiated Thyroid Cancer: The American Thyroid Association Guidelines Task Force on Thyroid Nodules and Differentiated Thyroid Cancer. Thyroid: Official Journal of the American Thyroid Association 26:1-133

17. Adam MA, Pura J, Goffredo P, Dinan MA, Reed SD, Scheri RP, Hyslop T, Roman SA, Sosa JA (2015) Presence and Number of Lymph Node Metastases Are Associated With Compromised Survival for Patients Younger Than Age 45 Years With Papillary Thyroid Cancer. J Clin Oncol 33:2370-2375

18. Zaydfudim V, Feurer ID, Griffin MR, Phay JE (2008) The impact of lymph node involvement on survival in patients with papillary and follicular thyroid carcinoma. Surgery 144:1070-1078

19. Hay ID, Johnson TR, Thompson GB, Sebo TJ, Reinalda MS (2016) Minimal extrathyroid extension in papillary thyroid carcinoma does not result in increased rates of either cause-specific mortality or postoperative tumor recurrence. Surgery 159:11-19

20. Ito Y, Tomoda C, Uruno T, Takamura Y, Miya A, Kobayashi K, Matsuzuka F, Kuma K, Miyauchi A (2006) Prognostic significance of extrathyroid extension of papillary thyroid carcinoma: massive but not minimal extension affects the relapse-free survival. World $\mathrm{J}$ Surg 30:780-786

21. Elsheikh TM, Asa SL, Chan JK, DeLellis RA, Heffess CS, LiVolsi VA, Wenig BM (2008) Interobserver and intraobserver variation among experts in the diagnosis of thyroid follicular lesions with borderline nuclear features of papillary carcinoma. Am J Clin Pathol 130:736-744

22. Hirokawa M, Carney JA, Goellner JR, DeLellis RA, Heffess CS, Katoh R, Tsujimoto M, Kakudo K (2002) Observer variation of encapsulated follicular lesions of the thyroid gland. Am J Surg Pathol 26:1508-1514

23. Lloyd RV, Erickson LA, Casey MB, Lam KY, Lohse CM, Asa SL, Chan JK, DeLellis RA, Harach HR, Kakudo K, LiVolsi VA, Rosai J, Sebo TJ, Sobrinho-Simoes M, Wenig BM, Lae ME (2004) Observer variation in the diagnosis of follicular variant of papillary thyroid carcinoma. Am J Surg Pathol 28:1336-1340

24. Howitt BE, Paulson VA, Barletta JA (2015) Absence of BRAF V600E in non-infiltrative, non-invasive follicular variant of papillary thyroid carcinoma. Histopathology 67:579-582

25. Kim TH, Park YJ, Lim JA, Ahn HY, Lee EK, Lee YJ, Kim KW, Hahn SK, Youn YK, Kim KH, Cho BY, Park DJ (2012) The association of the BRAF(V600E) mutation with prognostic factors and poor clinical outcome in papillary thyroid cancer: a meta-analysis. Cancer 118:1764-1773

26. Lim JY, Hong SW, Lee YS, Kim B-W, Park CS, Chang H-S, Cho JY (2013) Clinicopathologic Implications of the BRAFV600E Mutation in Papillary Thyroid Cancer: A Subgroup Analysis of 3130 Cases in a Single Center. Thyroid 23:1423-1430

27. Lupi C, Giannini R, Ugolini C, Proietti A, Berti P, Minuto M, Materazzi G, Elisei R, Santoro M, Miccoli P, Basolo F (2007) Association of BRAF V600E mutation with poor clinicopathological outcomes in 500 consecutive cases of papillary thyroid carcinoma. J Clin Endocrinol Metab 92:4085-4090 
28. Xing M, Alzahrani AS, Carson KA, Viola D, Elisei R, Bendlova B, Yip L, Mian C, Vianello F, Tuttle RM, Robenshtok E, Fagin JA, Puxeddu E, Fugazzola L, Czarniecka A, Jarzab B, O’Neill CJ, Sywak MS, Lam AK, Riesco-Eizaguirre G, Santisteban P, Nakayama H, Tufano RP, Pai SI, Zeiger MA, Westra WH, Clark DP, Clifton-Bligh R, Sidransky D, Ladenson PW, Sykorova V (2013) Association Between BRAF V600E Mutation and Mortality in Patients With Papillary Thyroid Cancer. JAMA 309: 1493-1501

29. Xing M, Westra WH, Tufano RP, Cohen Y, Rosenbaum E, Rhoden KJ, Carson KA, Vasko V, Larin A, Tallini G, Tolaney S, Holt EH, Hui P, Umbricht CB, Basaria S, Ewertz M, Tufaro AP, Califano JA, Ringel MD, Zeiger MA, Sidransky D, Ladenson PW (2005) BRAF mutation predicts a poorer clinical prognosis for papillary thyroid cancer. J Clin Endocrinol Metab 90:6373-6379

30. Gupta N, Dasyam AK, Carty SE, Nikiforova MN, Ohori NP, Armstrong M, Yip L, LeBeau SO, McCoy KL, Coyne C, Stang MT, Johnson J, Ferris RL, Seethala R, Nikiforov YE, Hodak SP (2013) RAS mutations in thyroid FNA specimens are highly predictive of predominantly low-risk follicular-pattern cancers. J Clin Endocrinol Metab 98:E914-E922

31. Medici M, Kwong N, Angell TE, Marqusee E, Kim MI, Frates MC, Benson CB, Cibas ES, Barletta JA, Krane JF, Ruan DT, Cho NL, Gawande AA, Moore FD, Jr., Alexander EK (2015) The variable phenotype and low-risk nature of RAS-positive thyroid nodules. BMC Med 13:184 